\title{
Pengendalian Gulma Perkebunan Kelapa Sawit (Elaeis guineensis Jacq.) di Perkebunan Padang Halaban, Sumatera Utara
}

\author{
Weeds Control on Oil Palm (Elaeis guineensis Jacq.) Plantation in Padang Halaban Estate, \\ North Sumatera
}

\section{Hari Prasetyo dan Sofyan Zaman*}

Departemen Agronomi dan Hortikultura, Fakultas Pertanian, Institut Pertanian Bogor (Bogor Agricultural University), Jl. Meranti, Kampus IPB Darmaga, Bogor 16680, Indonesia Telp. \& Faks. 62-251-8629353 e-mail agronipb@indo.net.id

*Penulis untuk korespondensi: sofyan_zaman@yahoo.co.id

Disetujui 18 Januari 2016/ Published online 25 Januari 2016

\begin{abstract}
The Intership activity was started from February to June 2014 in Padang Halaban Estate, North Sumatra. Observations of weed vegetation made with the analysis of vegetation in 4 blocks with different planting years to get summed dominance ratio (SDR) and index of similarity using Bray-Curtis index of similarity. The dominant weeds in 4 blocks belong to the group of grass. Weed vegetation in 4 blocks is not homogeneous. Blocks that have high levels of weed vegetation similarity to the farthest sequentially is this year plant, old mature plant, young mature plant and then immature plant. The cost of weed control in main nursery is higher than in pre nursery. The cost of weed control in immature plant is higher than in mature plant.
\end{abstract}

Keywords: cost, oil palm, Padang Halaban Estate, weeds control

\begin{abstract}
ABSTRAK
Kegiatan magang berlangsung dari bulan Februari hingga Juni 2014 di Perkebunan Padang Halaban, Sumatera Utara. Pengamatan vegetasi gulma dilakukan dengan analisis vegetasi pada 4 blok dengan tahun tanam yang berbeda untuk mendapatkan nisbah jumlah dominansi (NJD) dan koefisien komunitas menggunakan indeks kesamaan Bray-Curtis. Gulma yang dominan pada 4 blok termasuk ke dalam golongan rumput. Keempat blok memiliki vegetasi gulma yang tidak homogen. Blok yang memiliki kesamaan vegetasi gulma terdekat hingga terjauh secara berurut adalah blok tanaman tahun ini, tanaman menghasilkan tua, TM muda dan tanaman belum menghasilkan. Biaya pengendalian gulma di pembibitan utama lebih tinggi dibandingkan pre nursery. Biaya pengendalian di TBM lebih tinggi dibandingkan TM.
\end{abstract}

Kata kunci: biaya, Kebun Padang Halaban, kelapa sawit, pengendalian gulma 


\section{PENDAHULUAN}

Kelapa sawit (Elaeis guineensis Jacq.) merupakan salah satu komoditas perkebunan utama di Indonesia. Kelapa sawit telah memberikan peran penting pada perekonomian dan pembangunan Indonesia. Menurut Pahan (2008) sebanyak 85\% lebih pasar dunia kelapa sawit dikuasai Indonesia dan Malaysia. Berdasarkan kajian oleh Amir (2004), ekspor pertanian memiliki pengaruh yang positif terhadap pendapatan nasional. Menurut data yang dihimpun oleh Direktorat Jenderal Perkebunan, volume ekspor kelapa sawit Indonesia pada tahun 2013 mencapai 20572200 ton yang nilainya mencapai 15.8 trilyun USD. Perkebunan kelapa sawit juga mampu menciptakan lapangan pekerjaan sehingga menambah kesejahteraan masyarakat. Berdasarkan data yang dihimpun oleh Direktorat Jenderal Perkebunan luas total areal perkebunan kelapa pada tahun 2013 mencapai 9149919 ha.

Produksi CPO (Crude Palm Oil) Indonesia pada tahun 2013 Indonesia mencapai 24 431640 ton. Produksi yang tinggi tidak terlepas dari pengelolaan tanaman yang tepat. Pengelolaan tanaman tersebut meliputi kegiatan pembibitan, penanaman, pemupukan, pemanenan dan pengendalian OPT (Organisme Pengganggu Tanaman) seperti hama, penyakit tumbuhan dan gulma. Menurut PPKS (2010), areal yang didominasi oleh gulma yang berbahaya atau pesaing berat seperti sembung rambat (Mikania micrantha), alang-alang (Imperata cylindrica), dan Asystasia coromandeliana dapat menurunkan produksi sampai $20 \%$.

Menurut Setyamidjaja (2006) secara garis besar jenis-jenis gulma yang dijumpai pada perkebunan kelapa sawit dapat digolongkan menjadi gulma berbahaya dan gulma lunak. Gulma berbahaya adalah gulma yang memiliki daya saing tinggi terhadap tanaman pokok seperti ilalang (Imperata cylindrica), sembung rambat (Mikania cordata dan M. micrantha), lempuyangan (Panicum repens), teki (Cyperus rotundus), kirinyuh (Chromolaena odorata), harendong (Melastoma malabatrichum) dan tembelekan (Lantana camara). Gulma lunak adalah gulma yang keberadaannya dalam budi daya tanaman kelapa sawit dapat ditoleransi dan dapat menahan erosi tanah namun jumlahnya juga tetap harus dikendalikan. Contoh gulma lunak diantaranya babadotan (Ageratum conyzoides), rumput kipahit (Paspalum conjugatum), dan pakis (Nephrolephis biserrata). Menurut Sastroutomo (1990), pada lahan perkebunan tanahnya jarang mengalami pengolahan mempunyai jenis gulma tahunan yang komposisinya cukup besar dibandingkan dengan gulma semusim.

Gulma di perkebunan kelapa sawit selain menimbulkan persaingan dengan tanaman juga mengganggu kelancaran kegiatan kebun. Gulma di gawangan dapat menyulitkan pemanenan, pengutipan brondolan dan mengurangi efektivitas pemupukan. Gulma di pasar pikul dapan mengganggu pergerakan tenaga kerja. Kelancaran kegiatan yang terganggu dapat mengurangi produktivitas tenaga kerja (PPKS, 2010).

Kerugian yang diakibatkan oleh gulma tidak terlihat secara langsung. Beberapa faktor yang menyebabkan timbulnya kerugian akibat persaingan antara tanaman perkebunan dan gulma antara lain pertumbuhan tanaman terhambat sehingga waktu mulai berproduksi lebih lama, penurunan kuantitas dan kualitas hasil produksi tanaman, produktivitas kerja terganggu, gulma dapat menjadi sarang hama dan penyakit, serta biaya pengendalian gulma yang sangat mahal (Barus, 2003).

Menurut Alamprabu (2010), di Provinsi Jambi tercatat kerugian hasil pada komoditi kelapa sawit yang disebabkan oleh gulma Mikania micrantha sebesar Rp 38110500 dengan luas serangan 757.5 ha, kerugian akibat Imperata cylindrica sebesar Rp 59971500 dengan luas serangan 1086 ha, dan akibat Paspalum conjugatum sebesar Rp 43416599 dengan luas serangan 1149.9 ha.

Pengelolaan tanaman yang tepat merupakan kegiatan yang penting untuk meningkatkan produksi kelapa sawit. Pengendalian gulma merupakan salah satu kegiatan pengelolaan yang tidak kalah penting dibandingkan tindakan pengelolaan yang lain, maka perlu dilakukan tindakan pengendalian gulma yang efektif dan efisien.

Kegiatan magang ini bertujuan mengetahui permasalahan dan cara penyelesaian masalah mengenai pengendalian gulma pada perkebunan kelapa sawit serta mengetahui biaya yang dibutuhkan dalam pengendalian gulma.

\section{BAHAN DAN METODE}

Kegiatan magang dilaksanakan di Perkebunan Kelapa Sawit Padang Halaban Estate (PHLE), Kecamatan Aek Kuo, Kabupaten Labuhan Batu Utara, Provinsi Sumatera Utara. Kegiatan tersebut dilaksanakan selama empat bulan yang dimulai pada Februari hingga Juni 2014.

Kegiatan magang dilaksanakan dengan melakukan praktek kerja secara langsung di perkebunan kelapa sawit. Kegiatan yang 
dilaksanakan lebih diarahkan kepada aspek khusus pengendalian gulma. Terdapat beberapa peranan yang berbeda bagi mahasiswa untuk setiap bulannya.

Satu bulan pertama mahasiswa bertugas sebagai karyawan harian lepas (KHL). Mahasiswa melaksanakan kegiatan yang berubungan dengan aspek teknis seperti persiapan lahan, penanaman, pembibitan, pemupukan, pengendalian gulma, pemangkasan, pemanenan dan pengangkutan tandan buah segar (TBS). Mahasiswa melaksanakan kegiatan magang sebagai pendamping mandor pada satu bulan berikutnya. Kegiatan yang dilaksanakan terkait dengan aspek manajerial. Kegiatan yang dilaksanakan sebagai pendamping mandor meliputi pengawasan kegiatan di kebun, penentuan tenaga kerja dan biayanya, penentuan dosis, konsentrasi, dan jumlah bahan kimia yang digunakan, manajemen pengendalian gulma, manajemen pemanenan, serta pembuatan laporan pertanggungjawaban.

Dua bulan terakhir mahasiswa melaksanakan kegiatan magang sebagai pendamping asisten yang bertugas menyusun rencana kerja harian dan bulanan, mengevaluasi hasil kegiatan kebun, mengawasi semua pekerjaan yang dilakukan di lapangan (kontrol lapangan) untuk mengetahui cara penilaian hasil kerja mandor, dan membantu asisten dalam menyelesaikan administrasi kebun. Seluruh rangkaian kegiatan dicatat pada jurnal harian kegiatan magang.

Data yang dikumpulkan dalam kegiatan magang ini adalah data primer dan data sekunder. Pengumpulan data primer dilakukan melalui pengamatan pada saat mengikuti kegiatan di lapangan dengan cara mencatat seluruh kegiatan. Data tersebut meliputi dominansi jenis gulma, dosis dan konsentrasi herbisida yang digunakan, organisasi pengendalian gulma, ketepatan pelaksanaan pengendalian, jumlah HK yang dibutuhkan dan estimasi biaya pengendalian per tahun.

Pengambilan data dominansi jenis gulma dilakukan dengan analisis vegetasi dengan metode kuadrat $50 \mathrm{~cm}$ x $50 \mathrm{~cm}$ yang diambil secara acak tidak langsung. Pengambilan sampel dilaksanakan di 4 Blok dengan umur tanaman yang berbeda. Blok tersebut diantaranya adalah blok Tanaman Tahun Ini (TTI), blok Tanaman Belum Menghasilkan (TBM), blok Tanaman Menghasilkan (TM) muda (kurang dari 6 tahun), dan blok TM Tua. Di setiap blok dilakukan pengambilan 15 sampel. Data yang diambil pada setiap sampel kuadrrat diantaranya adalah kerapatan mutlak (KM), bobot basah mutlak $(\mathrm{BBM})$ dan frekuensi mutlak (FM). KM adalah jumlah individu spesies gulma tertentu dalam petak sampel. BBM adalah bobot basah spesies gulma tertentu dalam petak sampel. FM adalah jumlah petak sampel yang memuat spesies gulma tertentu.

Data sekunder diperoleh dari arsip perkebunan meliputi data kondisi kebun seperti peta areal, jenis tanah, iklim, topografi, populasi tanaman, data produksi dan produktivitas, curah hujan serta dosis rekomendasi herbisida pada kebun tersebut. Data standar dan target kebun meliputi pemeliharaan, pemanenan, produksi dan tenaga kerja. Selain itu juga data non teknis meliputi organisasi dan manajemen kebun.

Data yang diperoleh dianalisis menggunakan metode deskriptif dengan membandingkan hasil yang diperoleh dengan standar operasional dan aturan kerja yang berlaku. Dominansi jenis gulma dihitung dengan menggunakan Nisbah Jumlah Dominansi (NJD) setiap jenis gulma yang diperoleh. NJD dihitung dengan rumus (Fitriana et al. 2013):

$$
\mathrm{NJD}=\frac{K N+B B N+F N}{3}
$$

KN merupakan kerapatan nisbi yaitu nilai KM spesies gulma tertentu dibagi total KM semua jenis gulma. BBN merupakan bobot basah nisbi yaitu nilai BBM spesies gulma tertentu dibagi total BBM semua jenis gulma. FN merupakan frekuensi nisbi yaitu nilai FM spesies gulma tertentu dibagi total FM semua jenis gulma. NJD menunjukkan kemampuan suatu jenis gulma tertentu untuk menguasai sarana tumbuh yang ada.

Kemudian setiap blok dibandingkan tingkat kesamaan vegetasi gulmanya dengan menghitung koefisien komunitas (KK) menggunakan indeks kesamaan Bray-Curtis (Ludwig dan Reynolds 1988). KK dihitung dengan rumus:

$$
\mathrm{KK}=\frac{2 W}{a+b} \times 100 \%
$$

Nilai $\mathrm{W}$ adalah jumlah individu terendah dari spesies gulma yang terdapat di 2 blok yang dibandingkan. Nilai a adalah jumlah semua individu dari spesies gulma pada blok pertama, dan $b$ adalah jumlah semua individu dari spesies gulma pada blok kedua. KK menunjukkan tingkat kesamaan antara 2 blok yang dibandingkan. Kemudian tingkat kesamaan tersebut ditampilkan dalam bentuk dendrogram. 


\section{HASIL DAN PEMBAHASAN}

Vegetasi Gulma

Nisbah jumlah dominansi. Analisis vegetasi dilakukan pada 4 blok dengan umur tanaman berbeda. Analisis vegetasi gulma di TTI diambil di Blok ex-12 divisi I dengan tahun tanam 2014. Blok tersebut merupakan blok replanting. Analisis vegetasi gulma di TBM di ambil di Blok 50 divisi II dengan tahun tanam 2013. Analisis vegetasi gulma di TM muda diambil di Blok 39 divisi II dengan tahun tanam 2010. Umur tanaman telah mencapai 4 tahun. Analisis vegetasi gulma di TM tua diambil di Blok 34 divisi II dengan tahun tanam 1999. Umur tanaman telah mencapai
15 tahun. Pelemparan kuadrat dilakukan sebanyak 15 kali sehingga diperoleh 15 petak contoh untuk setiap blok. Hasil analisis vegetasi gulma disajikan dalam Tabel 1.

Berdasarkan hasil dari analisis vegetasi pada Tabel 1, gulma yang paling dominan pada blok TTI adalah Axonopus compressus dengan NJD $37.30 \%$. Gulma yang paling dominan pada blok TBM adalah Ottochloa nodosa dengan NJD $63.60 \%$. Gulma yang paling dominan pada blok TM muda adalah Cynodon dactylon dengan NJD $32.47 \%$. Gulma yang paling dominan pada blok TM tua adalah Axonopus compressus dengan NJD $29.72 \%$. Spesies gulma yang paling dominan pada 4 blok tersebut termasuk ke dalam golongan rumput.

Tabel 1. Nilai NJD gulma berdasarkan analisis vegetasi pada 4 blok yang berbeda tahun tanam

\begin{tabular}{|c|c|c|c|c|c|}
\hline \multirow{2}{*}{ No } & \multirow{2}{*}{ Jenis Gulma } & \multicolumn{4}{|c|}{ NJD per Lokasi (\%) } \\
\hline & & TTI & TBM & TM muda & TM Tua \\
\hline & Rumput & & & & \\
\hline 1 & Axonopus compressus & 37.30 & 8.35 & 11.34 & 29.72 \\
\hline 2 & Cynodon dactylon & 6.09 & 1.98 & 32.47 & 3.19 \\
\hline 3 & Ottochloa nodosa & & 63.60 & & 18.83 \\
\hline 4 & Paspalum conjugatum & & 2.48 & & 0.68 \\
\hline 5 & Eleusine indica & & 2.88 & 7.29 & \\
\hline 6 & Echinochloa colona & & & 2.19 & \\
\hline \multirow[t]{3}{*}{7} & Setaria plicata & & & & 0.60 \\
\hline & Subtotal & 43.39 & 79.30 & 53.29 & 53.03 \\
\hline & Daun lebar & & & & \\
\hline 8 & Borreria alata & 14.63 & 2.34 & 1.46 & 5.48 \\
\hline 9 & Urena lobata & 12.25 & 2.97 & 2.26 & 3.69 \\
\hline 10 & Cleome rutidosperma & 4.41 & 6.45 & 3.79 & \\
\hline 11 & Melastoma malabathricum & 3.15 & & & \\
\hline 12 & Mimosa pudica & 2.77 & 0.78 & 3.48 & 2.23 \\
\hline 13 & Ageratum conyzoides & 0.55 & & & 0.60 \\
\hline 14 & Asystasia intrusa & 0.53 & 1.81 & & \\
\hline 15 & Phyllanthus niruri & 0.52 & 0.72 & & 1.10 \\
\hline 16 & Euphorbia hirta & & 0.69 & 1.62 & \\
\hline 17 & Amaranthus spinosus & & & 4.22 & \\
\hline 18 & Singonium sp. & & & 0.49 & 14.01 \\
\hline 19 & Peperomia pellucida & & & 0.59 & \\
\hline 20 & Mimosa invisa & & & & 1.26 \\
\hline 21 & Clidemia hirta & & & & 1.28 \\
\hline 22 & Kacangan & & & & 0.62 \\
\hline \multirow[t]{3}{*}{23} & Kentosan & 6.75 & 1.40 & 1.06 & 0.72 \\
\hline & Subtotal & 45.58 & 17.17 & 18.97 & 30.99 \\
\hline & Teki & & & & \\
\hline 24 & Cyperus kyllingia & 9.15 & 3.53 & 22.80 & 10.71 \\
\hline 25 & Cyperus rotundus & 1.32 & & 4.94 & \\
\hline \multirow[t]{2}{*}{26} & Cyperus iria & 0.56 & & & \\
\hline & Subtotal & 11.03 & 3.53 & 27.74 & 10.71 \\
\hline & Pakis & & & & \\
\hline 27 & Nephrolepis biserrata & & & & 2.72 \\
\hline 28 & Stenochlaena palustris & & & & 1.32 \\
\hline \multirow[t]{3}{*}{29} & Diplazium asperum & & & & 1.22 \\
\hline & Subtotal & & & & 5.27 \\
\hline & Total & 100.0 & 100.0 & 100.0 & 100.0 \\
\hline
\end{tabular}


Jumlah gulma golongan rumput yang tertinggi terdapat pada blok TBM dengan jumlah $79.30 \%$. Jumlah gulma golongan daun lebar yang tertinggi terdapat pada blok TTI dengan jumlah $45.58 \%$. Jumlah gulma golongan teki yang tertinggi terdapat pada blok TM muda dengan jumlah $27.74 \%$. Gulma golongan pakis hanya ditemui pada blok TM tua dengan jumlah 5.27\%.

Koefisien komunitas. Koefisien
komunitas (KK) merupakan nilai yang menunjukkan kesamaan komunitas vegetasi gulma dari 2 areal atau komunitas yang berbeda. Semakin tinggi nilai KK maka semakin homogen vegetasi gulma dari 2 komunitas (blok) yang dibandingkan. Nilai KK dari 4 blok yang telah dilakukan analisis vegetasi disajikan dalam Tabel 2.

Menurut Fitriana et al. (2013) dan Pandia (2011), dua komunitas dinyatakan homogen jika nilai $\mathrm{KK} \geq 75 \%$ dan heterogen jika $<75 \%$. Vegetasi gulma di antara TTI, TBM, TM muda dan TM tua tidak ada yang homogen. Hal tersebut disebabkan seluruh nilai $\mathrm{KK}$ yang diperoleh kurang dari $75 \%$. Vegetasi gulma yang memiliki kesamaan paling tinggi adalah TTI dengan TM Tua dengan nilai KK sebesar $53.56 \%$. Vegetasi gulma yang memiliki kesamaan paling rendah adalah TBM dengan TM Muda dengan nilai KK sebesar $15.59 \%$.

Tabel 2. Nilai koefisien komunitas berdasarkan analisis vegetasi dari 2 komunitas yang berbeda

\begin{tabular}{llc}
\hline Komunitas 1 & Komunitas 2 & $\begin{array}{c}\text { Nilai Koefisien } \\
\text { Komunitas }(\%)\end{array}$ \\
\hline TTI & TBM & 16.55 \\
TTI & TM Muda & 34.56 \\
TTI & TM Tua & 53.56 \\
TBM & TM Muda & 15.59 \\
TBM & TM Tua & 29.83 \\
TM Muda & TM Tua & 26.02 \\
\hline
\end{tabular}

Berdasarkan nilai KK yang telah diperoleh, dapat disusun dendrogram kesamaan komunitas. Dendrogram pada Gambar 1 menunjukkan seberapa dekat jarak kesamaan komunitas dari 4 blok yang dilakukan analisis vegetasi. Vegetasi gulma di TTI dan TM Tua memiliki jarak kesamaan paling dekat, sedangkan vegetasi gulma di TBM memiliki jarak kesamaan paling jauh dengan 3 vegetasi lainnya. Komunitas yang memiliki kesamaan vegetasi gulma terdekat hingga terjauh secara berurut adalah TTI, TM Tua, TM muda dan TBM.

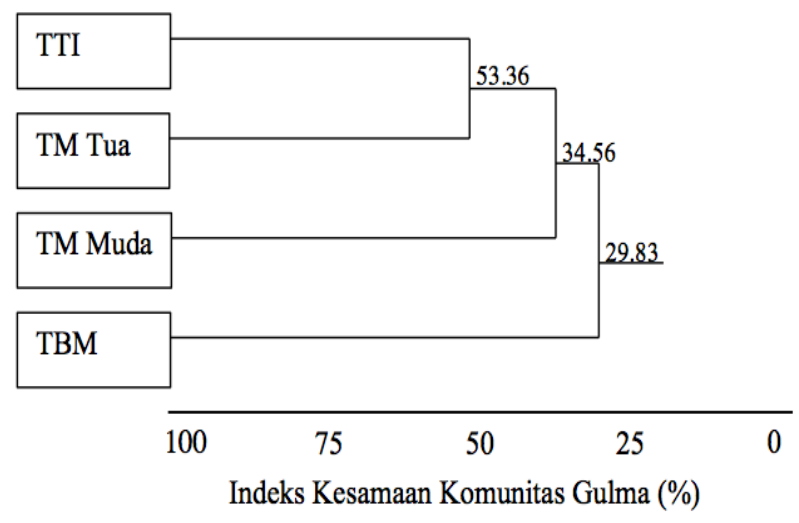

Gambar 1. Dendrogram kesamaan komunitas gulma dari 4 blok dengan umur tanaman yang berbeda

\section{Semprot Anak Kayu}

Semprot anak kayu di PHLE merupakan kegiatan yang tidak rutin dilaksanakan. Semprot anak kayu dilaksanakan jika populasi anak kayu sudah terlalu banyak sehingga tidak dapat dikendalikan dengan dongkel anak kayu. Anak kayu adalah gulma daun lebar yang memiliki batang berkayu. Herbisida yang digunakan adalah Garlon 670 EC (Triklopyr) + Erkafuron 20 WG (metil metsulfuron). Gulma yang menjadi sasaran adalah Clidemia hirta, Urena lobata dan Melastoma malabatrichum.

Pelaksanaan semprot anak kayu di beberapa divisi tidak dilakukan dengan sebagaimana mestinya. Herbisida yang digunakan hanya Garlon tanpa tambahan Erkafuron. Kemudian mandor perawatan tidak melakukan survei pada hari sebelum dilakukannya penyemprotan. Hal tersebut mengakibatkan tidak efektifnya kegiatan semprot anak kayu yang dilakukan.

Berdasarkan pengamatan, gulma anak kayu yang telah disemprot menunjukkan gejala sepeti terbakar 5-7 hari setelah semprot, namun pada 4 minggu setelah aplikasi, gulma yang disemprot tidak mati (Gambar 2).

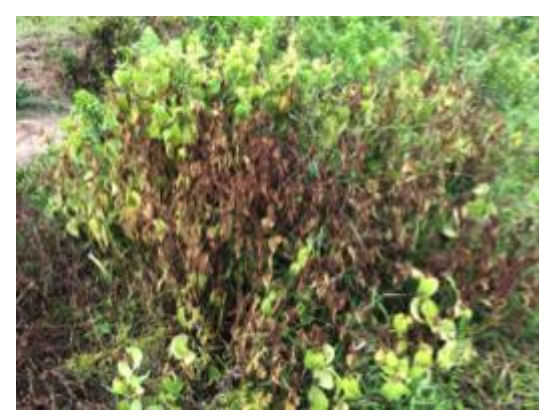

Gambar 2. Hasil semprot anak kayu 4 minggu setelah aplikasi 
Efek dari herbisida yang diberikan tidak bereaksi menyeluruh pada gulma sehingga gulma dapat tumbuh kembali. Hal tersebut berakibat pada penggunaan herbisida dan tenaga kerja yang sia-sia.

\section{Penggunaan Alat Pelindung Diri}

Tenaga kerja pengendalian gulma, khususnya tenaga semprot diharuskan memakai APD secara lengkap, tetapi dalam pelaksanaannya banyak tenaga kerja yang tidak memakai secara lengkap (Gambar 3). Tenaga semprot hanya memakai baju pelindung dan masker tanpa pelindung wajah, sarung tangan dan apron. Pelindung wajah yang berbahan plastik tembus pandang tidak digunakan dengan alasan menyulitkan bernafas dan menghalangi pandangan karena uap air dari pernafasan. Sarung tangan dan apron dinilai menyulitkan pelaksanaan semprot karena membuat panas. Asisten dan mandor 1 beberapa kali mengingatkan mandor semprot saat lingkaran pagi untuk mengawasi penggunaan APD, namun dalam pelaksanaannya mandor semprot membiarkan tenaga semprotnya tidak memakai APD secara lengkap.

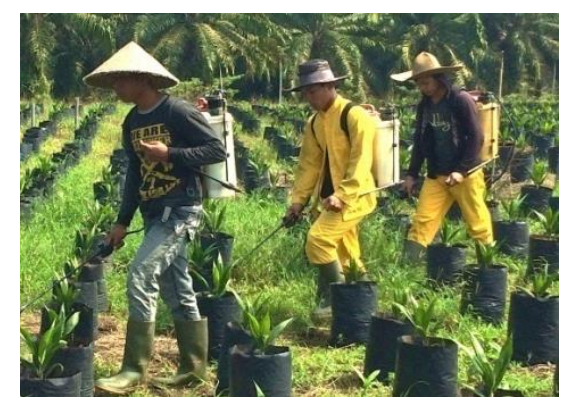

Gambar 3. Tenaga semprot tidak menggunakan APD secara lengkap

\section{Estimasi Biaya Pengendalian Gulma}

Pengendalian gulma merupakan salah satu kegiatan perawatan di perkebunan kelapa sawit yang memerlukan biaya yang tinggi. Selain upah tenaga kerja, pengendalian gulma juga menggunakan bahan berupa herbisida yang harganya relatif mahal. Biaya pengendalian gulma didapatkan dengan menghitung upah tenaga kerja dan biaya herbisida dari jumlah rotasi dalam satu tahun. Data diperoleh dari kegiatan pengendalian yang rutin dilaksanakan dan diskusi dengan asisten kebun. Biaya pengendalian gulma yang penulis rangkum berdasarkan data yang diperoleh di lapangan disajikan pada Tabel 3 dan Tabel 4.

Biaya pengendalian gulma di pembibitan Main nursery lebih besar dibandingkan Pre Nursery. Hal tersebut disebabkan gulma pada Pre
Nursery dikendalikan hanya secara manual dengan cara dicabut tanpa pengendalian secara kimiawi. Pre Nursery tidak memerlukan areal yang begitu luas sehingga tidak memerlukan tenaga kerja dalam jumlah yang banyak, sedangkan pengendalian gulma di Main Nursery dilakukan secara manual dan kimiawi menggunakan herbisida untuk mengendalikan gulma di antara Polybag.

Tabel 3. Estimasi biaya pengendalian gulma di pembibitan

\begin{tabular}{lc}
\hline \multicolumn{1}{c}{ Tahapan } & Biaya (Rp 1000 bibit $^{-1}$ tahun $\left.^{-1}\right)$ \\
\hline Pre Nursery & 142885 \\
Main & \\
Nursery & 451352 \\
\hline Total & 594237 \\
\hline
\end{tabular}

Biaya pengendalian di TBM lebih tinggi dibandingkan TM. Hal tersebut disebabkan populasi gulma pada TBM lebih tinggi dibandingkan TM. Populasi gulma yang tinggi tentu memerlukan biaya pengendalian yang lebih tinggi. Biaya pengendalian yang tinggi pada TBM adalah pengendalian secara manual. Pengendalian tersebut adalah garuk piringan. Garuk piringan di lahan TBM dilakukan dengan rotasi 6 kali dalam satu tahun.

Tabel 4. Estimasi biaya pengendalian gulma di lapangan

\begin{tabular}{lrlr}
\hline \multirow{2}{*}{ Fase Tanaman } & \multicolumn{3}{c}{$\begin{array}{c}\text { Biaya Pengendalian Gulma } \\
\left.\text { (Rp ha } \text { tahun }^{-1}\right)\end{array}$} \\
\cline { 2 - 4 } & Manual & \multicolumn{1}{c}{ Kimia } & \multicolumn{1}{c}{ Total } \\
\hline TBM $^{*}$ & 1216512 & 455517 & 1672029 \\
TM & 135168 & 360108 & 495276 \\
\hline
\end{tabular}

Keterangan: * Biaya belum termasuk penanaman LCC di TBM

Penanaman Legume Cover Crop (LCC) di lapangan membutuhkan perawatan ekstra. Perawatan ekstra tersebut menimbulkan biaya baru diluar biaya pengendalian gulma. Biaya tersebut dimulai dari pembibitan LCC, penanaman, dan perawatan hingga populasi LCC telah menutupi tanah secara penuh. Analisis biaya dari penanaman LCC terhadap biaya pengendalian gulma membutuhkan analisis yang lebih mendetail. Maka perlu dilakukan analisis lebih lanjut mengenai biaya pembibitan, penanaman dan perawatan LCC terhadap biaya pengendalian gulma di perkebunan kelapa sawit.

\section{KESIMPULAN}

Berdasarkan hasil analisis vegetasi, gulma yang dominan di areal TM tua adalah Axonopus 
compressus. Gulma yang dominan di areal TM muda adalah Cynodon dactylon. Gulma yang dominan di areal TBM adalah Ottochloa nodosa. Gulma yang dominan di areal TTI adalah Axonopus compressus. Spesies-spesies gulma tersebut termasuk golongan rumput. Masingmasing komunitas yang dibandingkan memiliki vegetasi gulma yang tidak homogen. Blok yang memiliki kesamaan paling tinggi adalah TTI dengan TM Tua. Komunitas yang memiliki kesamaan vegetasi gulma terdekat hingga terjauh secara berurut adalah TTI, TM Tua, TM muda dan TBM.

Pengendalian di pembibitan main nursery membutuhkan biaya yang lebih tinggi dibandingkan di pre nursery. Pengendalian di areal TBM membutuhkan biaya yang lebih tinggi dibandingkan dengan pengendalian di areal TM. Pengendalian gulma di PHLE dilakukan dengan cukup baik, namun di beberapa divisi kurangnya pengawasan dalam kegiatan semprot anak kayu mengakibatkan hasil yang kurang efektif. Kemudian kesadaran tenaga semprot akan bahaya herbisida dan pengawasan terhadap penggunaan APD kurang diperhatikan.

\section{DAFTAR PUSTAKA}

Amir, H. 2004. Pengaruh ekspor pertanian dan nonpertanian terhadap pendapatan nasional. Kajian Ekonomi dan Keuangan. 8(4):101-115.

Alamprabu, D. 2010. Pengelolaan gulma pada perkebunan kelapa sawit. Berita Utama [Internet]. [diunduh 2013 Nov 12]). Tersedia pada: http://ditjenbun.deptan. go.id/perlindungan/berita-196 pengelolaan-gulma-pada-perkebunankelapa-sawit.html.

Barus, E. 2003. Pengendalian Gulma di Perkebunan, Efektivitas dan Efisiensi Aplikasi Herbisida. Yogyakarta (ID): Kanisius.

[Ditjenbun] Direktorat Jenderal Perkebunan. 2013. Perkembangan Luas Areal $\begin{array}{llll}\text { Perkebunan } 2008 \quad- & 2013\end{array}$ [Internet]. [diunduh 2014 Jul 13]. Tersedia pada http://ditjenbundeptan.go. id/tinymcpuk/gambar/file/Luas_Areal_Est imasi_2013.pdf.
[Ditjenbun] Direktorat Jenderal Perkebunan. 2013. Perkembagan Produksi Komoditi Perkebunan 2008 - 2013 [Internet]. [diunduh 2014 Jul 13]. Tersedia pada: http://ditjenbun.deptan.go.id/tinymcpuk/g ambar/file/ Produksi_Estimasi_2013.pdf.

[Ditjenbun] Direktorat Jenderal Perkebunan. 2014. Perkembangan Volume dan Nilai Ekspor Komoditas Primer Perkebunan Tahun 2008 - 2013 [Internet]. [diunduh 2014 Jul 13]. Tersedia pada http://ditjenbun.pertanian.go.id/tinymcpuk /gambar/file/5.\%20 Ekspor.pdf.

Fitriana, M., Parto, Y., Munandar, Budianta, D. 2013. Pergeseran jenis gulma akibat perlakuan bahan organik pada lahan kering bekas tanaman jagung (Zea mays L.). J Agron Indonesia. 41(2): 118-125.

Ludwig, J.A., Reynold, J.F. 1988. Statistical Ecology: A Primer on Methods and Computing. New York (US): John Wiley \& Sons Inc.

Pahan, I. 2008. Panduan Lengkap Kelapa Sawit, Manajemen Agribisnis dari Hulu hingga Hilir. Jakata (ID): Penebar Swadaya.

Perdana, E. 2009. Pengendalian gulma kelapa kawit (Elaeis guineensis Jacq.) di Kebun Bukit Pinang, PT Bina Sains Cemerlang, Minamas Plantation, Kabupaten Musi Rawas, Propinsi Sumatera Selatan [skripsi]. Bogor (ID): Institut Pertanian Bogor.

Pandia, J.A. 2011. Aplikasi herbisida dalam persiapan lahan dan frekuensi pengendalian gulma terhadap pertumbuhan dan produksi jagung (Zea mays L.) selatan [skripsi]. Bogor (ID): Institut Pertanian Bogor.

[PPKS] Pusat Penelitian Kelapa Sawit. 2010. Budi Daya Kelapa Sawit. Jakarta (ID): PT Balai Pustaka.

Sastroutomo, S.S. 1990. Ekologi Gulma. Jakarta (ID): PT Gramedia Pustaka Utama.

Sembodo, D.R.J. 2010. Gulma dan Pengelolaannya. Yogyakarta (ID): Graha Ilmu.

Setyamidjaja, D. 2006. Seni Budi Daya, Kelapa Sawit. Yogyakarta (ID): Kanisius. 